\title{
Epidemiological Aspects and Differential Diagnosis of the Cutaneous Round Cell Tumors in Dogs
}

\author{
Roxana CORA, Adrian Florin GAL*, Marian TAULESCU, Flaviu TĂBĂRAN, Andras NAGY, Mihai NEGRU, \\ Cornel CĂTOI
}

Faculty of Veterinary Medicine, University of Agricultural Sciences and Veterinary Medicine, 3-5

Mănăştur Street, 3400 Cluj-Napoca, Romania;

*corresponding author: adrian.gal@usamvcluj.ro

Bulletin UASVM Veterinary Medicine 74(1) / 2017,

Print ISSN 1843-5270; Electronic ISSN 1843-5378

DOI:10.15835/buasvmcn-vm: 12591

\begin{abstract}
Round cell neoplasms (RCNs) are frequent cutaneous lesions in dogs, with high percentages among skin tumors. In this category are included histiocytoma, mast cell tumor, plasmacytoma, lymphoma and transmissible venereal tumor. The aim of the study was to perform an epidemiological study with reference to the cutaneous round cell tumors in a period of 10 years in the Department of Pathology (Faculty of Veterinary Medicine, ClujNapoca, Romania). Additionally, in the recorded cases with round cell tumors (mast cell tumor, histiocytoma and lymphoma) we described the main histological and cytological features. The epidemiological data were collected from the records of Pathology Department between 2005-2014. The investigation included dogs diagnosed with cutaneous round cell neoplasms, following necropsy analysis or assessment of biopsies or cytological samples. All collected specimens were analyzed by histopathological and/or cytological techniques. The staining used for histological investigation were Hematoxylin-eosin, Masson's trichrome and Toluidine blue, whereas Diff Quikand Wright methods were utilized in cytological specimens. The distribution of the cutaneous round cell tumors in relation to age, breed and sex was also assessed. The most frequent round cell tumor type was the mast cell tumor $(19.54 \%)$ followed by histiocytoma $(11.33 \%)$ and lymphoma (1.98\%). The round cell tumors recorded were equally distributed in both males and females. Concerning the distribution of cutaneous RCNs by age (average age), histiocytoma occurred in 5 years old subjects, mast cell tumor in 11.9 years old subjects, and lymphoma in 6 years old subjects. Mast cell tumor was more frequent in stray dogs and Boxer breed, while histiocytoma occurred more commonly in stray dogs. Histological and cytological analysis was mandatory to perform the differential diagnosis between RCNs. Microscopic details concerning cytoplasm and nucleus of tumoral cells, together with the displaying mode in histological specimens may reveal the type of RCN. Cutaneous round cell tumors had an increased incidence, aspect observed in other reports too. The differential diagnosis has to rely on some specific microscopical features that can suggest the type of RCN.
\end{abstract}

Keywords: dog, epidemiology, round cell tumors, skin

\section{INTRODUCTION}

Distinct round cell neoplasms (RCNs) are mainly composed of hemolymphatic system cells. Their name derives from the appearance of the cells, which usually have a round shape and are arranged individually. However, round cells are not always found only in round cell tumors and can be found in other neoplasms too. For example, a number of epithelial and some poorly differentiated mesenchymal tumors may consist oval to round neoplastic cells. One of the main characteristics of round cell tumors is the lack of intercellular junctions. The arrangement of cell in groups is not typical for round cell neoplasms, they usually have an individual arranging (DeNicola, 2008; DeNicola, 2014).

Cytological smears made of round cell tumors contain numerous small to medium-sized round cells, arranged individually. Mast cell tumors, lymphomas, histiocytomas, transmissible venereal 


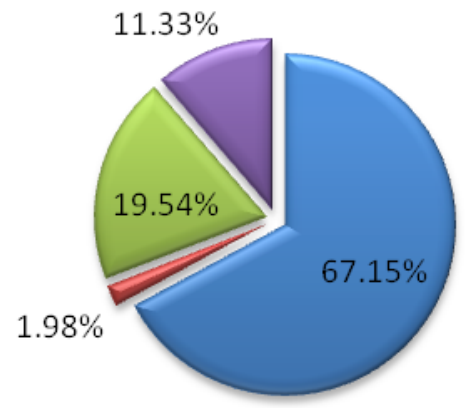

\author{
$\square$ Other skin tumors \\ - Lymphoma \\ $\square$ Mast cell tumor \\ - Histiocytoma
}

Fig.1. The percentage of lymphomas, mast cell tumors and histiocytomas out of all skin tumors.

tumors (Sticker's sarcomas) and extramedullary plasmacytomas are the most common round cells tumors that can occur within the skin (Duncan and Prasse, 1976; Duncan and Prasse, 1979; Rebar, 1978; Barton, 1987; Villiers, 2003; Tyler et al., 2008).

Sometimes, melanomas and basal cell tumors can display the appearance found in cutaneous round cell tumors (Tyler et al., 2008).

However, Fisher (2014) included the histiocytic sarcoma in the category of cutaneous round cell tumors.

In this paper we conducted an epidemiological study concerning canine cutaneous RCNs (i.e., lymphomas, mast cell tumors, histiocytomas) that were diagnosed in the Pathology Department (Faculty of Veterinary Medicine, Cluj-Napoca, Romania) in 2005-2014 period. The main cytological and histopathological findings were also described in each skin tumors diagnosed. Mast cell tumors were classified in three grades of malignancy, according to the Patnaik system.

\section{MATERIALS AND METHODS}

The epidemiological study was conducted over a period of 10 years (2005-2014), using case records of the Pathology Department (Faculty of Veterinary Medicine, Cluj-Napoca, Romania). Canine cases with cutaneous RCNs (lymphoma, mast cell tumor, histiocytoma) were identified. Assessed tumors originated either from corpses or from surgically removed biopsies that were sent for histological analysis. Cytological specimens were also included in this analysis. Histological sections were performed using the standard paraffin technique, which were then stained using the Hematoxylin-eosin(HE), Masson's trichrome (MT) and Toluidine blue(TB) methods. Cytological smears were achieved by fine needle aspiration method or by impression. The obtained smears were stained by Diff-Quik (DQ) or Wright techniques. The mast cell tumors were sorted according to their differentiation degree in three histological grades, following Patnaik classification (Patnaik et al., 1984).

\section{RESULTS AND DISCUSSION}

Out of all dogs assessed in this study, 34\% were diagnosed with different types of tumors. The percentage of skin tumors was high, representing $25.86 \%$ of the total tumors identified in this species. Data from the literature also indicate an increased incidence of skin tumors, especially among dogs, which accounted around one third of all tumors of this species (Baba and Cătoi, 2007; Vail and Withrow, 2007).

However, cutaneous RCNs (lymphoma, histiocytoma, mast cell tumor) accounted about $32.86 \%$ of all skin tumors. In Figure 1 is shown the $\%$ distribution of suggested skin tumors in dogs.

Between the period 2005-2014, cutaneous lymphomas represented $1.98 \%$ of all skin tumors. As a comparison, other reports suggested that cutaneous lymphoma (epitheliotrophic and nonepitheliotrophic forms) was detected in only $1 \%$ of all canine skin tumors (Goldschmidt and Shofer, 1992; Fontaine et al., 2009). We have diagnosed both epitheliotrophic skin lymphomas (57.15\%), as well as non-epitheliotrophic lymphomas (42.85\%). Blackwood (2003) states that in dogs, epitheliotrophic lymphoma is more common than non-epitheliotrophic form. In our records, the cutaneous lymphoma was identified in the following breeds (in relatively equal proportion): Saint Bernard, Rottweiler, Cocker Spaniel, English Bulldog, German Shepherd Dog. A predisposition of a number of dog breeds for cutaneous nonepitheliotrophic lymphoma has been reported, 
together with Boxer, Saint Bernard, Basset Hound, Irish Setter, Cocker Spaniel, German Shepherd Dog, Golden Retriever and Scottish Terrier. In the case of epitheliotrophic lymphoma, no breed predisposition has been reported (Blackwood, 2003).

After performing this study, no sex predisposition for cutaneous lymphoma have been observed, aspect mentioned by other authors (Blackwood, 2003; Gross et al., 2005).

In our study, the average age of canine subjects that displayed cutaneous lymphoma was around 6 years. Some papers suggested that cutaneous epitheliotrophic lymphoma is more commonly diagnosed in old dogs, with an average age of 11 years (ranging from 6 to 14 years) (Moore et al., 1994; Gross et al., 2005).

As regards the cutaneous mast cell tumors, they have been noticed in $19.54 \%$ of all skin tumors. This percentage is consistent with the data cited in the literature that reports an incidence of 16-21\% (Murphy, 2003).The following dog breeds were more affected: stray dogs, Boxer, German Shepherd Dog, Golden Retriever, Poodle, American Pit Bull Terrier and Great Dane. According to some reports, mast cell tumors can occur in any breed, with a higher prevalence in Boxer, Staffordshire Bull Terrier, Labrador Retriever, Golden Retriever, Weimeraner and Schnauzer (Vail and Withrow, 2001; Murphy, 2003).

Concerning the distribution of mast cell tumors by sex, no significant differences were noticed in this sense, aspect recorded by other authors too(Murphy, 2003). However, the average age formast cell tumors occurrence in dogs was 11.9 years. Our data showed that cutaneous mast cell tumor was more common in middle-aged dogs, but it can be diagnosed at any age (from 3 weeks to 19 years; Murphy, 2003).

Cutaneous histiocytoma was recorded in about $11.33 \%$ of all canine skin tumors. In this tumor type, we achieved equivalent values to those reported in the literature that mention an incidence of 10\% (Morris and Dobson, 2001).

After processing the information from our records, we noticed that stray dogs, Poodle, Fox Terrier, Schnautzer, Rottweiler, Vizsla, French Bulldog, Cocker Spaniel and Beagle breeds are among the most predisposed to develop histiocytomas. In this sense, Blackwood (2003) mentions that the more predisposed breeds to develop this tumor type are Boxer, Bulldog, Doberman and Dachshund. The incidence of cutaneous histiocytoma was slightly higher in males $(52.95 \%)$ compared to females $(47.05 \%)$. Nevertheless, some authors have observed no predilection for this neoplasm by sex (Gross et al., 2005).

Regarding distribution of histiocytomas according to age, we noticed a high number of cases in 1-year-old subjects (around the specified age), with an average of 5 years. As suggested by some other studies, histiocytoma is more common in young dogs, about $50 \%$ of all histiocytomas occurring in dogs up to the age of 2 years (Morris and Dobson, 2001).The incidence of cutaneous histiocytoma greatly decreases after the age of 3 years, but it is a tumor that can be seen at any age (Gross et al., 2005).

Next, we present some of the main cytological features of the studied tumors.

The cutaneous lymphoma (Fig. 2C), was characterized by a moderate to high cellularity degree, with a homogeneous population of cells belonging to the lymphoid lineage. Tumor cells are large, polymorphous, round to oval, with large nuclei, situated eccentrically. The N:C ratio is high and the mitosis were rarely observed.

In the case of mast cell tumors (Fig. 2A), the following cytological aspects were noticed: smears had moderate to high cell numbers, tumor cells were large, uniform, round or slightly oval, with a very granulated cytoplasm, round to oval centrally located nuclei; the $\mathrm{N}: \mathrm{C}$ ratio was high and small nucleoli were observed. The suggested cellular details have been observed in well-differentiated mast cell tumors. Poorly differentiated mast cell tumors were characterized by a polymorphous cell population, with large polymorphic nuclei and rare intracytoplasmic granules. However, another characteristic aspect of mast cell tumors assessed was the presence of eosinophils among tumor cells.

In cutaneous histiocytoma, the cytological smears displayed a high number of spherical cells, with a moderate to low anisocytosis, central or eccentrically located nuclei with a round/oval to kidney shape aspect. The chromatin was uniformly distributed, whereas the nucleoli were small and poorly visible in most cases (Fig. 2B). Cellular cytoplasm was moderate to abundant, finely granular and basophilic. Other cells observed 


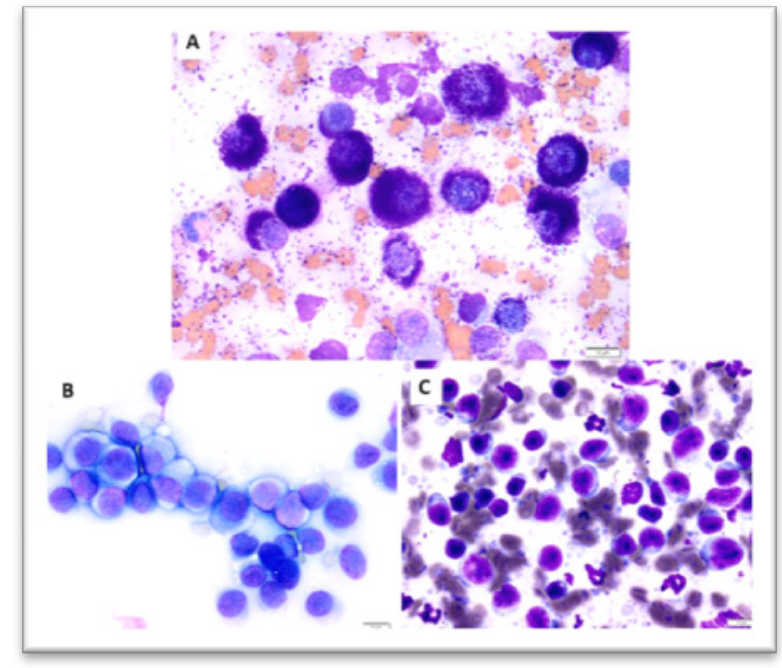

Fig. 2. Cytological aspects of cutaneous RCNs: A) Mast cell tumor: round to oval cells, abundant cytoplasmatic granules, few eosinophils (Wright stain); B)

Histiocytoma: abundant slightly basophilic cytoplasm, granular chromatin (Wright stain); C) Lymphoma: polymorphic cells, large nuclei situated eccentrically, multiple and uneven nucleoli, and rare neutrophils (DQ stain).

in the mass of the cutaneous histiocytoma were lymphocytes, plasma cells and macrophages. According to some reports, the presence of a large number of small lymphocytes in cytological samples from histiocytomas may suggest the spontaneous regression of the neoplasm (Fisher, 2014).

Following the evaluation of tissue sections from cases with cutaneous histiocytoma, the following features were observed: round to oval neoplastic cells with oval or kidney-shaped nuclei and moderate to abundant acidophilic and foamy cytoplasm. In the tumor mass, the cells were displayed in rows, cords or small groups, with a discrete sustaining stroma (Fig. 3). In most cases, the mitotic index was high (about 3-5 divisions/40x magnified field). In some investigated histiocytomas, more or less infiltrate with tumor cells was noticed in the dermal epidermal junction and in the subcutaneous tissue. However, some areas with apoptotic cells and intratumor necrosis were identified in the mass of some histiocytomas, most of such tumors being infiltrated with lymphocytes (aspects that may suggest regression). Additionally, a number of histiocytomas presented inflammatory cells associated with epidermis ulceration.

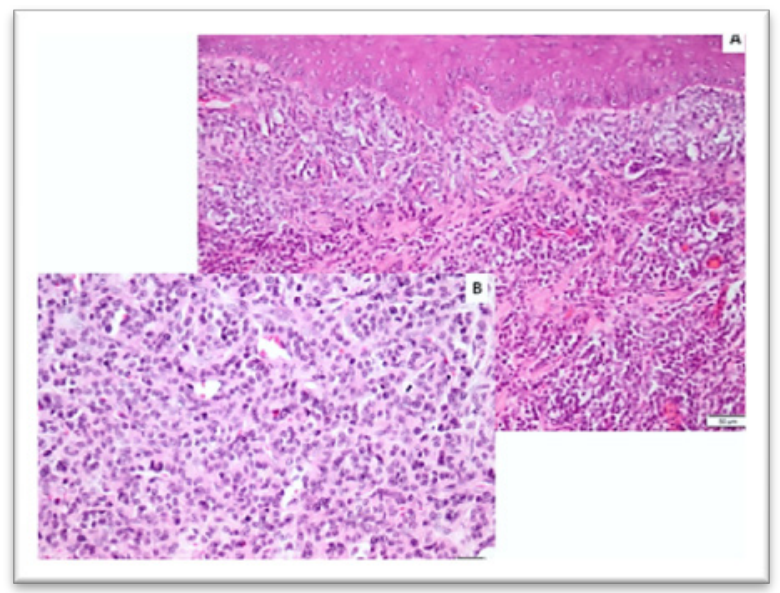

Fig. 3. Cutaneous histiocytoma: presence of tumor cells arranged in cords and nests, numerous mitotic cells and acidophilic aspect of the cytoplasm in neoplastic cells (HE stain).

Ginn et al. (2007) states that most cutaneous histiocytomas are benign and can be treated by surgical removal of the mass. However, it have been suggested that such tumors can regress spontaneously, in few weeks after onset.

Using the Patnaik grading system, cutaneous mast cell tumors were classified into three grades of malignancy as follows: grade I (well differentiated mast cell tumors), grade II (moderate differentiated mast cell tumors) and grade III (poorly differentiated mast cell tumors) (Patnaik et al., 1984).

In this study, grade I mast cell tumors were diagnosed in $45 \%$ of dogs, grade II mast cell tumors in $30 \%$ of individuals, while grade III mast cell tumors in the remaining 25\% of cases. Generally, in highly differentiated mast cell tumors (Fig. 4 ), cellular proliferation occurred in the dermis, most of cells adopting a spherical shape with one small centrally located nucleus. Additionally, abundant intracytoplasmatic granules and distinct cytoplasmic borders were observed. Most neoplasms displayed a compact cellular mass, with cells set in rows or groups separated by thin collagen strands. Other histological findings are: low mitotic index, no skin ulceration, minimal 


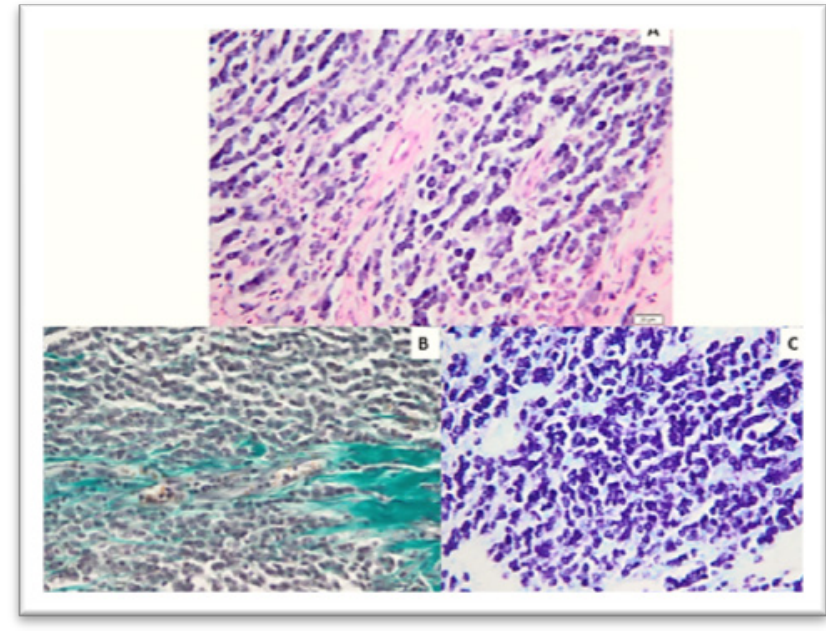

Fig. 4. Grade I mast cell tumors: A) Tumor cells arranged in cords, abundant intracytoplasmic granules, low cellular polymorphism (HE stain);B) Characteristic distribution in cords among collagen fibers (MT stain);C) Intense staining of the intracytoplasmic granules (TB stain).

swelling and presence of eosinophils inside the tumor.

Ginn et al. (2007) suggested that this type of cancer occurred in approximately $50 \%$ of all canine cases recorded with mast cell tumors, most of them having a benign behavior. Their surgical removal is usually curative, with a survival time of about 4 years in more than $90 \%$ of cases (Ginn et al., 2007).

Grade II mast cell tumors (Fig. 5) were located either in the deep part of dermis or in the subcutaneous connective tissue. Tumor cells were round to oval in shape, some of them binucleated (or giant-cells appearance). Comparing to highly differentiated mast cell tumors an increase in the $\mathrm{N}: \mathrm{C}$ ratio was observed, with few intracytoplasmic granules and distinct cytoplasmic borders. The arrangement of tumoral cells was in cords or groups separated by a collagenous stroma, which in some cases was impregnated with hyaline. The mitotic index was low in such tumor type.

Other histologic features are: areas of intracellular edema, necrosis and infiltration with eosinophils.

Some reports indicated that moderate differentiated mast cell tumors can have a favorable prognosis (if treated appropriately) as in the case of highly differentiated mast cell tumors (Seguin et al., 2001; Weisse et al., 2002; Murphy, 2003). The

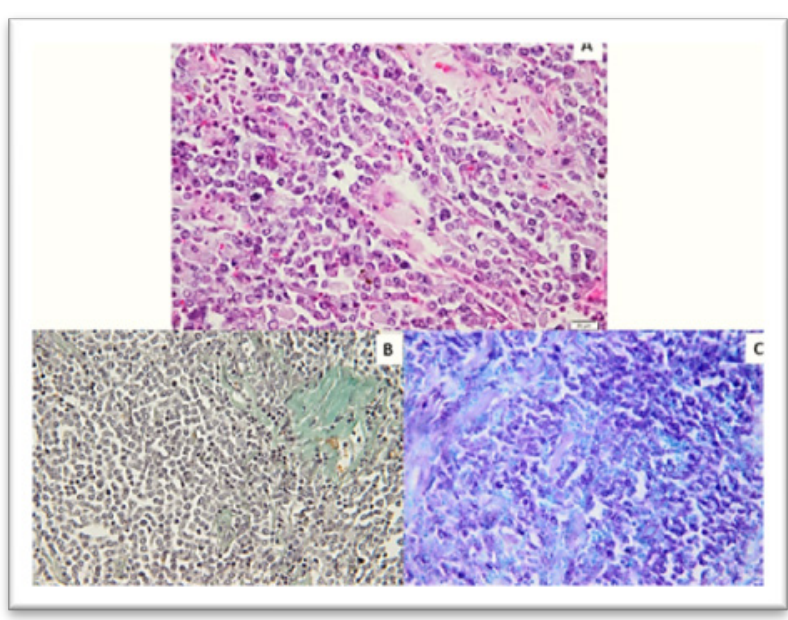

Fig. 5. Grade II mast cell tumors: A) Tumor cells arranged in cords, modest polymorphism; moderate intracytoplasmatic granules, rare eosinophils (HE stain); B) Tumor cells arranged in cords (MT stain); C) Faintly stained intracytoplasmic metachromatic granules (TB stain).

survival rate is around 3.5 years in about $55 \%$ of subjects (Ginn et al., 2007).

Grade III mast cell tumors (Fig. 6) were characterized by the presence of tumor cells set in cords that get in the subcutaneous tissue, or even deeper. As regards the main histological features of poorly differentiated mast cells tumors, the following aspects were detected: high cellular polymorphism, moderate anisokaryosis, presence of multiple nucleoli, numerous binucleated or giant cells, fine or poorly detectable intracytoplasmic granules, increased N:Cratio, indistinctcytoplasmic boundaries. The mitotic index was high, with some tumor-associated lesions being noticed as well, i.e. intercellular edema, necrosis and/or hemorrhage. As in the other mast cell tumor types, eosinophils were identified in between tumor cells. In order to establish the diagnosis, faintly expressed intracytoplasmic granules become evident with the aid of Toluidine-blue staining (Fig. 6C).

According to some other reports, it seems that about $20 \%$ of all mast cell tumors are poorly differentiated. In about $15 \%$ of dogs diagnosed with this type of mast cell tumors, the survival rate was about 3.5 years (Ginn et al., 2007). More than $75 \%$ of poorly differentiated mast cell tumors have the potential to metastasize (Murphy, 2003).

In epitheliotrophic cutaneous lymphomas, medium-sized round tumor cells were noticed, with poorly defined margins, euchromatic nuclei, 


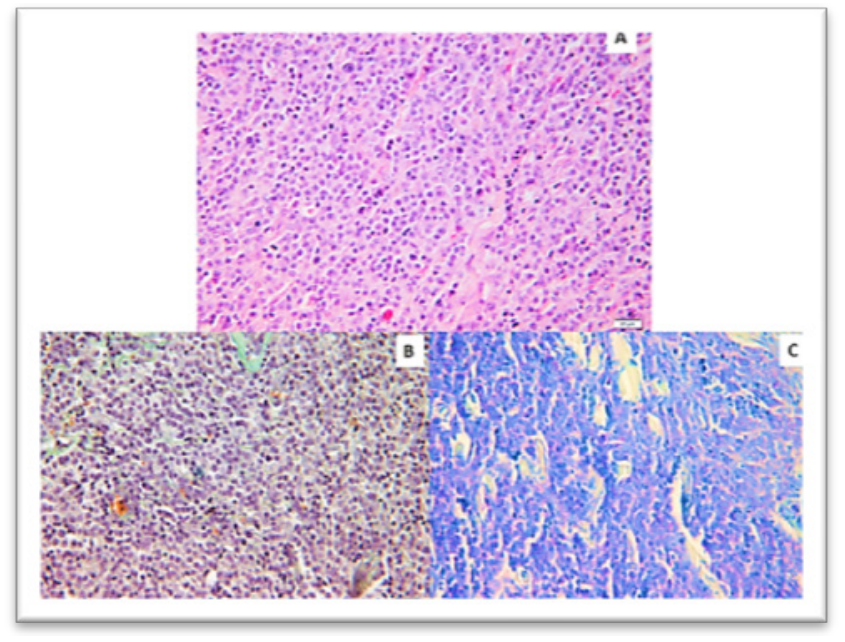

Fig. 6. Grade III mast cell tumors: A) Tumor cells with high polymorphism, fine or absent cytoplasmic granules, numerous mitoses (HE stain); B) The presence of intercellular edema (MTstain); C) Discrete staining of the intracytoplasmic metachromatic granules (TB stain).

moderate amount of cytoplasm and numerous mitoses. Some cells invaded the epidermis and some dermal adnexial structures. Tumoral lymphocytes located in the epidermis had a diffuse growth pattern, or formed aggregates known as Pautrier microabscesses. Other histological features identified in this tumor type were moderate acanthosis, hyperkeratosis, ulceration and inflammation.

Since the epitheliotrophic lymphoma is a progressive disease, none of the chemotherapeutic protocols influenced the long-term clinical outcome. The evolution of the disease in dogs varies from several months to approximately 2 years. Sometimes, the neoplasm may extend to lymph nodes or other organs (Gross et al., 2005; Moore et al., 1994).

In non-epitheliotrophic lymphomas (Fig. 7), the tumoral infiltrate was located in the superficial dermis, which induced the epidermal atrophy. Tumoral lymphocytes are polymorphic, with large uneven nuclei and an increased N:C ratio.

Most cutaneous non-epitheliotrophic lymphomas have a rapid progression, with metastasis in a number of lymph nodes (Gross et al., 2005; Moore et al., 1998).

\section{CONCLUSION}

In our investigation, canine cutaneous round cell tumors (mast cell tumor, histiocytoma

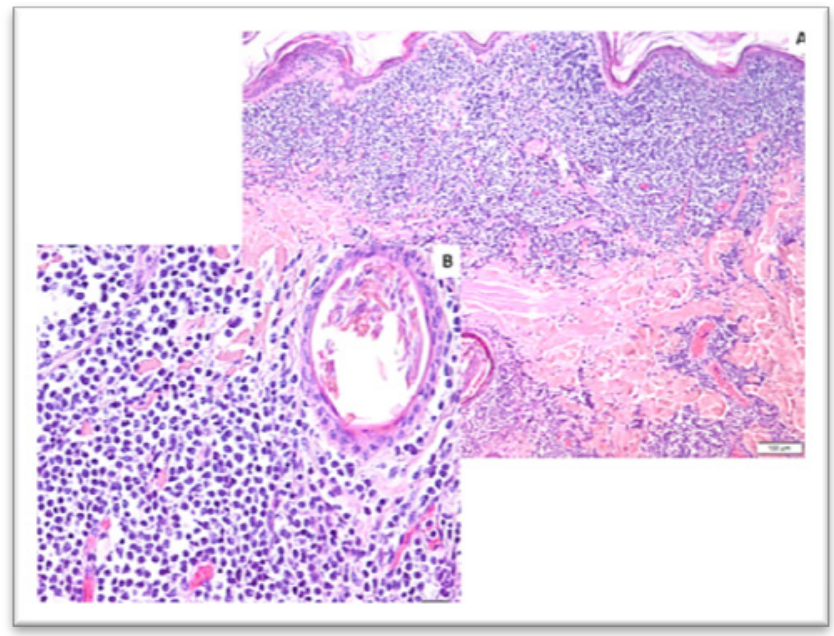

Fig.7. Nonepitheliotropic lymphoma, tumor cell infiltration in the superficial dermis and epidermal atrophy (HE stain).

and lymphoma) were frequently diagnosed, representing around one third (32.86\%) of all skin tumors, aspect presented by some other reports too. Concerning the distribution of RCNs by age (average age), histiocytoma and lymphoma occurred in young to mean age subjects, whereas mast cell tumors were diagnosed in older dogs. In mast cell tumors, the highest incidence was in stray dogs and Boxer breed, while histiocytoma was diagnosed more frequent in stray dogs. The differential diagnosis in RCNs should rely on some specific microscopical features and special staining procedures, to establish the final diagnosis. Microscopic details concerning cytoplasm and nucleus of tumoral cells, together with the displaying mode in histological specimens may reveal the type of RCN.

\section{REFERENCES}

1. Baba AI, Cătoi C (2007). Comparative oncology. The Publishing House of Romanian Academy, 127-198.

2. Barton C (1987). Cytologic diagnosis of cutaneous neoplasia: an algorithmic approach. Comp Cont Ed 9:2033.

3. Blackwood L (2003). Multifocal neoplastic skin disease, p. 168-178. In: Dubson JM., Lascelles BDX (Eds.). BSAVA Manual of Canine and Feline Oncology. $2^{\text {th }}$ ed. BSAVA.

4. DeNicola DB (2008). Round Cell, p. 68-77. In: Cowell RL, Tyler RD, Meinkoth JH, DeNicola DB (Eds.). Diagnostic Cytology and Hematology of the Dog and Cat. $3^{\text {th }}$ ed. Elsevier. 
5. DeNicola DB (2014). Round Cells, p. 70-79. In: Cowell RL, Valenciano AC (Eds.). Cowell and Tyler's Diagnostic Cytology and Hematology of the Dog and Cat. $4^{\text {th }}$ ed. Elsevier, St Louis.

6. Duncan JS, Prasse KW (1976). Cytologic examination of the skin and subcutis. Vet Clin North Am 6:637-645.

7. Duncan JS, Prasse KW (1979). Cytology of canine cutaneous round cell tumors. Vet Pathol 16:673-679.

8. Fisher DJ (2014). Cutaneous and Subcutaneous Lesions, p. 80-109. In: Cowell RL, Valenciano AC (Eds.). Cowell and Tyler's Diagnostic Cytology and Hematology of the Dog and Cat. $4^{\text {th }}$ ed. Elsevier, St Louis.

9. Fontaine J, Bovens C, Bettenay S, Mueller RS (2009). Canine cutaneous epitheliotropic T-cell lymphoma: a review. Vet Comp Oncol 7 (1): 1-14.

10. Ginn PE, Mansell JEKL, Rakich PM (2007). Skin and appendages, p. 768-776. In: Maxie MG (Eds.). Jubb, Kennedy, and Palmer's Pathology of Domestic Animals. $5^{\text {th }}$ ed. Saunders Elsevier.

11. Goldschmidt MH, Shofer FS (1992). Skin Tumors of the Dog and Cat, Oxford, Pergamon Press, 252 - 264.

12. Gross T, Ihrke PJ, Walder EJ, Affolter VK (2005). Skin Diseases of the Dog and Cat: Clinical and Histopathologic Diagnosis. $2^{\text {th }}$ ed. Blackwell Science Ltd, 837-888.

13. Moore PF, Affolter VK, Olivry T, Schrenzel MD (1998). The use of immunological reagents in defining the pathogenesis of canine skin diseases involving proliferation of leukocytes, p. 77-94. In: Kwochka KW, Willemse T, von Tscharner C (Eds.). Advances in Veterinary Dermatology. Butterworth-Heinemann, Oxford.

14. Moore PF, Olivry T, Naydan D (1994). Canine cutaneous epitheliotropic lymphoma (mycosis fungoides) is a proliferative disorder of CD8+ $\mathrm{T}$ cells. Am J Pathol 144:421-429.
15. Morris J, Dobson J (2001). Small Animal Oncology. $1^{\text {st }}$ ed. Blackwell, Oxford, 59-68.

16. Murphy S (2003). Mast cell tumours, p. 161-167. In: Dubson JM, Lascelles BDX (Eds.). BSAVA Manual of Canine and Feline Oncology. $2^{\text {th }}$ ed. BSAVA.

17. Patnaik AK, Ehler WJ, MacEwen EG (1984). Canine Cutaneous Mast Cell Tumor: Morphologic Grading and Survival Time in 83 Dogs. Vet Pathol 21:469-474.

18. Rebar AH (1978). Handbook of veterinary cytology. St. Louis, MO, Ralston Purina Co, 28-43.

19. Seguin B, Leibman NF, Bregazzi VS, Ogilvie GK, Powers BE, Dernell WS, Fettman MJ, Withrow SJ (2001). Clinical outcome of dogs with grade-II mast cell tumors treated with surgery alone: 55 cases (1996-1999). JAVMA 218:1120-1123.

20. Tyler RD, Cowell RL, Meinkoth JH (2008). Cutaneous and Subcutaneous Lesions, p. 78-111. In: Cowell RL, Tyler RD, Meinkoth JH, DeNicola DB (Eds.). Diagnostic Cytology and Hematology of the Dog and Cat. $3^{\text {th }}$ ed. Elsevier.

21. Vail DM, Withrow S (2001). Tumours of the skin and subcutaneous tissues, p. 233-273. In Withrow S, MacEwan E (Eds.). Small Animal Clinical Oncology. $3^{\text {th }}$ Edition, WB Sauders, Philadelphia.

22. Vail DM, Withrow SJ (2007). Tumors of the Skin and Subcutaneous Tissues, p. 375-401. In: Vail DM, Withrow SJ (Eds.). Whithrow \& MacEwen's Small Animal Clinical Oncology. $4^{\text {th }}$ ed. Saunders.

23. Villiers E (2003). Cytology, p. 24-37. In: Dubson JM., Lascelles BDX (Eds.). BSAVA Manual of Canine and Feline Oncology. $2^{\text {th }}$ ed. BSAVA.

24. Weisse C, Shofer F, Sorenmo K (2002). Recurrence rates and sites for grade II canine cutaneous mast cell tumors following complete surgical excision. JAAHA 38:71-73. 